\title{
Composite Membranes with Nanofibrous Cross-hatched Supports for Reverse Osmosis Desalination
}

\author{
Seungju Kim, ${ }^{\dagger}$ Daniel E. Heath, ${ }^{\ddagger}$ Sandra E. Kentish. ${ }^{\dagger} *$ \\ tDepartment of Chemical Engineering, The University of Melbourne, Parkville, VIC 3010, Australia. \\ ‡Department of Biomedical Engineering, The University of Melbourne, Parkville, VIC 3010, Australia. \\ KEYWORDS: reverse osmosis, electrospinning, membrane, cross-hatched supports, polyamide.
}

\begin{abstract}
A novel membrane structure comprised of cross-hatched electrospun nanofibers is developed. We illustrate that this novel structure allows for much higher water permeability when used as a support for reverse osmosis thin-film composite membranes. Reinforcement and lamination of the aligned nanofibres generates mechanically robust structures that retain very high porosity and low tortuosity when applied to high pressure seawater desalination operations. The cross-hatched nanofibre layers support the polyamide active layer firmly and reduce resistance to water flow due to the high porosity, low tortuosity, high mechanical strength and minimal thickness of the structures. The nanofibre composite membrane gives a water flux significantly greater than when a traditional support layer is used, at $99 \pm 5 \mathrm{~m}^{-2} \mathrm{~h}^{-1}$ with $\mathrm{NaCl}$ rejection of $98.7 \%$ at 15.5 bar.
\end{abstract}

\section{INTRODUCTION}

Water scarcity is listed as one of the largest global risks, requiring the development of inexpensive, effective, and industrially scalable desalination technology. Desalination has become a promising approach for producing fresh water in the face of global population growth and rapid industrialisation; however, it is still considered a cost- and energy-intensive technology. ${ }^{2-6}$ Desalination using reverse osmosis (RO) has continuously grown its installed capacity worldwide, largely replacing the traditional distillation process, as distillation consumes much larger quantities of energy. RO processes use hydraulic pressure from pumps to generate a flow of clean water through a membrane. The energy requirement for seawater RO (SWRO) in the 1970's was over $15 \mathrm{kwh} / \mathrm{m}^{3}$, but has been reduced to $2.5-3.5$ $\mathrm{kwh} / \mathrm{m}^{3}$ due to technological innovations such as high efficiency pumps and energy recovery systems. ${ }^{8}$ However, this requirement is still higher than the theoretical absolute minimum of $1.06 \mathrm{kwh} / \mathrm{m}^{3}$ at a typical recovery of $50 \%{ }^{9}$ Similarly, the typical energy intensity for brackish water RO (BWRO) is currently $0.8-2.5 \mathrm{kwh} / \mathrm{m}^{3}$ but the theoretical minimum is $0.4-0.7 \mathrm{kwh} / \mathrm{m}^{3} .^{10-11}$ The disparity between current energy demand and the theoretical minimum illustrates that additional technological advances are required. In current RO processes, the energy cost is around $30 \%$ of the entire process cost. This can be significantly reduced by developing novel membranes with higher water flux and less resistance to flow. ${ }^{9}$

RO membranes are typically prepared as a thin-film composite consisting of three layers; a non-woven fabric for mechanical strength, a microporous supporting layer and an ultrathin polyamide (PA) active layer on the top surface for separation. ${ }^{12-14}$ Increasing the water flux of typical thin-film composite (TFC) membranes by reducing the thickness of their selective layers has been a focal subject in RO membrane research, and membranes with extremely thin PA selective layers $(\sim 100 \mathrm{~nm})$ have been fabricated at industrial scale. ${ }^{8}$ However, very little research has been done to engineer the microporous supporting layer. Currently this layer is typically comprised of an asymmetric structure formed by phase inversion. The resulting layer provides mechanical strength and an even surface to support the ultrathin active layer. As thinner active layers with greater water permeability are developed, the portion of the total membrane resistance in the supporting layer becomes significant and reduces the total permeability of the membranes, clearly illustrating the need to engineer a new generation of supporting layers to further improve the efficiency and effectiveness of RO.

Electrospinning is a voltage-driven process capable of producing non-woven mats comprised of randomly aligned nanofibres, and the technique has been extensively used in biomedical research to generate scaffolds for tissue engineering. ${ }^{15-18}$ However, electrospun nanofibre membranes have also demonstrated a great potential for water processing due to their high porosity $(70-90 \%)$ and low tortuosity. ${ }^{7,}$ 19-22 In laboratory studies of desalination by membrane distillation or forward osmosis, the use of electrospun membranes leads to high water flux under low hydraulic pressure conditions. ${ }^{7,19-21}$ Moreover, the use of electrospun membranes in pressure retarded osmosis can efficiently generate energy driven by a salinity gradient from waste seawater brine. In most membrane processes, except membrane distillation, electrospun nanofibres act as supporting layers and PA active layers are formed on 
top. However, the use of nanofibre membranes has not been suitable for high pressure processes such as SWRO, which operate around 50 bar, because the nanofibre structures cannot provide the necessary mechanical strength, resulting in failure of the active layer during operation. ${ }^{19,23}$ For example, nanofibre composite membranes of PA on a polyacrylonitrile (PAN) nanofibre support were used for pressure retarded osmosis at a maximum 15.2 bar. However, higher pressures resulted in the breakage of the membrane. ${ }^{19}$ PA membranes with more linear structures on a PAN nanofibre support were also studied, but the water flux suddenly increased above 10.3 bar, implying mechanical failure of the active layer. ${ }^{23}$ Standard electrospinning deposits randomly oriented fibres. However, more well-controlled fibre architectures have been developed. Specifically, the use of parallel plate electrodes or rotating collectors has enabled the fabrication of structures with highly aligned fibres for use in microelectronics, photonics, and biomedical applications. ${ }^{24-26}$ Additionally, these structures show increased mechanical properties in the direction of fibre orientation compared to randomly aligned structures. ${ }^{27-29}$

The fundamental hypothesis tested in this contribution is that new electrospinning techniques can result in novel fibre structures, and that these novel structures can allow electrospun supports to be used in mid-to-high pressure membrane processing with higher water flow and lower energy consumption compared to traditional supports, a hypothesis that is supported by the data presented herein. Specifically, we report composite membranes containing a support layer of cross-hatched nanofibres (CNFs) of polysulfone (PSU) that were fabricated through the deposition of alternating layers of aligned fibres with orthogonal orientations (Figure 1).

The support layer was used with a polyester non-woven substrate and a PA active layer to make a composite membrane. These materials were selected as they are the most common materials for conventional TFC membranes for RO desalination processes, providing facile translation to commercial application. PSU nanofibres with diameter of $650 \mathrm{~nm}$ were fabricated using solution-based electrospinning on a rotating drum mandrel for fibre alignment. These structures provided low tortuosity and great strength, allowing the fabrication of thinner supports to minimise membrane resistance. PA layers were successfully fabricated on CNF supports by interfacial polymerisation and the CNF membranes were characterised for RO membrane processes. The novel nanofibre composite membrane displayed increased water flux and salt rejection as compared to a conventional thin film composite membrane and showed improved mechanical properties under high hydraulic pressure conditions as compared to a typical electrospun membrane.

\section{(a)}
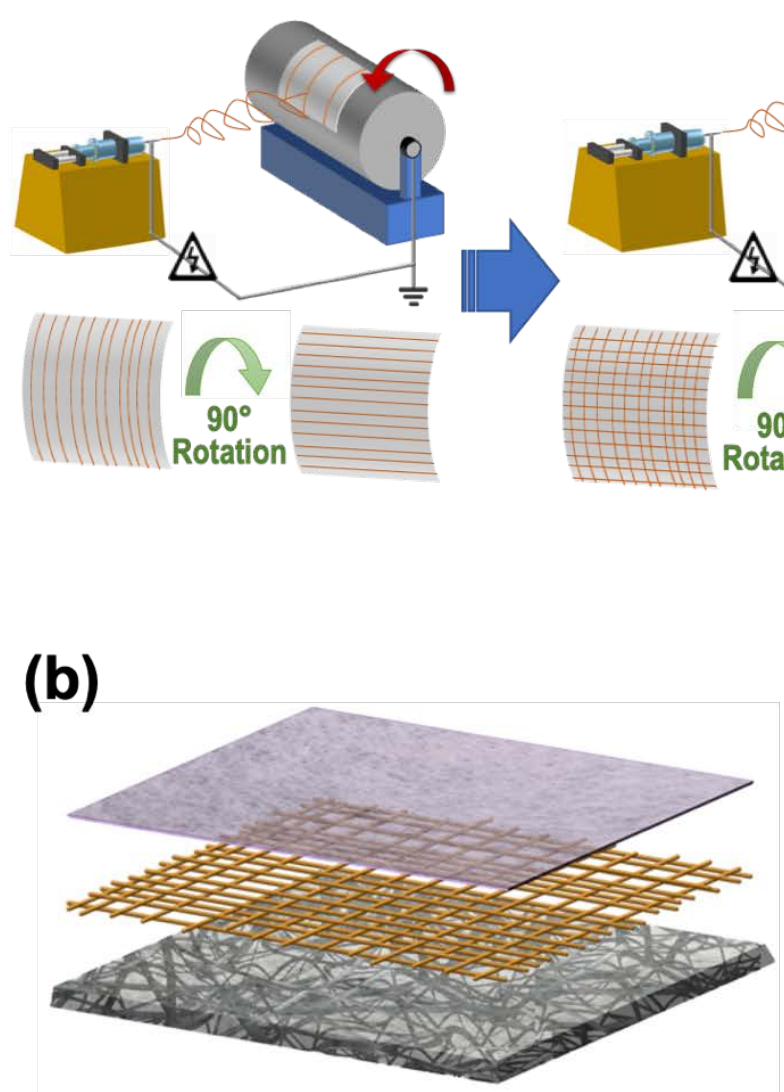

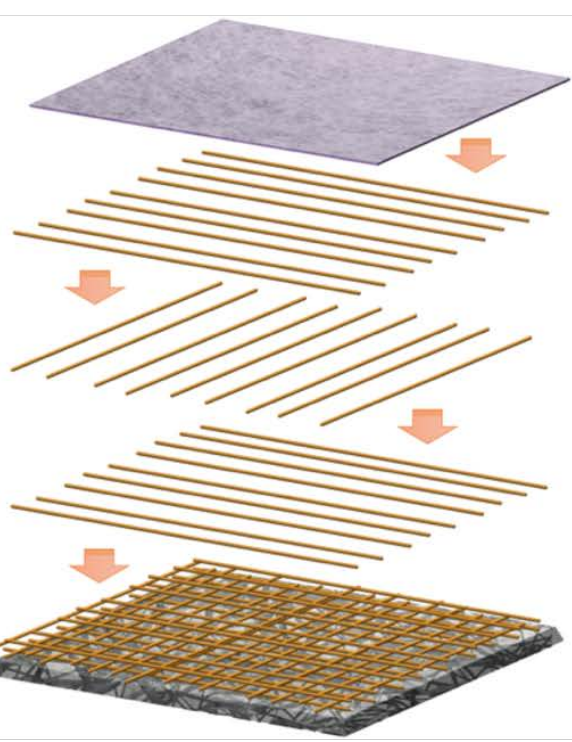

(c)

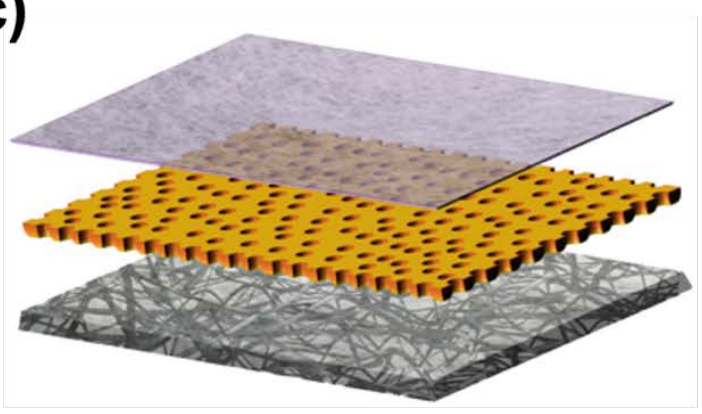

Figure 1. A schematic illustration of a cross-hatched electrospun composite membrane in the hypothetically ideal case, showing (a) the method to prepare a cross-hatched structure, (b) a nanofibre composite membrane with a cross-hatched supporting layer, (c) a conventional thin-film composite (TFC) membrane. 


\section{EXPERIMENTAL SECTION}

Materials. Ultrason S6010 Polysulfone (PSU) from BASF (Ludwigshafen, Germany) was used to prepare the nanofibres. Trimesoyl chloride (TMC, 98\%), mPhenylenediamine (MPD, 99\%), Dopamine hydrochloride, Tris(hydroxymethyl)aminomethane (Tris), N,NDimethylacetamide (DMAc, 99.8\%), Tetrahydrofuran (THF, $\geq 99.9 \%$ ), and n-hexane ( $\geq 99.0 \%$ ) were purchased from Sigma-Aldrich (St Louis, MO) and used without further purification. Hydrochloric acid $(\mathrm{HCl})$ and sodium chloride $(\mathrm{NaCl})$ were purchased from Chem-Supply (Gillman, Australia). DMAc and THF were used as solvents for electrospinning, dopamine hydrochloride and Tris were used for hydrophilic treatment of nanofibre supports, and TMC, MPD and n-Hexane were used for PA interfacial polymerisation. Purified water was prepared using a Millipore Milli$\mathrm{Q}^{\circledR}$ Integral Water Purification System (Burlington, MA).

Fabrication of nanofibre supports in cross-hatched structures. Nanofibre supports in cross-hatched structures were fabricated on polyester non-woven substrates using electrospinning of aligned nanofibres. $18 \mathrm{wt} \%$ solution of Ultrason S6010 PSU was prepared in a co-solvent of DMAc and THF $(1: 1 \mathrm{v} / \mathrm{v})$ at room temperature by vigorous stirring. After complete dissolution, the solution was maintained at room temperature overnight for degassing. The polymer solution was then placed into a syringe pump (Adelab Scientific) connected to a single spray needle tip within an electrospinning device consisting of a high voltage power supply from Spellman (CZE1000R, Hauppauge, $\mathrm{NY}$ ), and a rotating steel drum mandrel with diameter of $15 \mathrm{~cm}$ and length of $15 \mathrm{~cm}$. The tangential speed of the drum surface was varied from $1 \mathrm{~m} / \mathrm{s}$ to $16 \mathrm{~m} / \mathrm{s}$ by controlling the rotation speed of the drum to observe the effect of rotating rate on nanofibre alignment. From these studies, a tangential speed of $13 \mathrm{~m} / \mathrm{s}$ was selected for aligned nanofibre preparation. The tip-to-collector distance was fixed at $10 \mathrm{~cm}$ and the tip was moved on a rail at a rate of 100 $\mathrm{mm} / \mathrm{min}$ using a Linear Translation Stage from Thorlabs Inc. (Newton, NJ). The needle was charged at $12 \mathrm{kV}$ and the solution injection rate was fixed to $1.5 \mathrm{~mL} / \mathrm{hr}$. A square coupon of polyester non-woven fabric $(15 \mathrm{~cm} \mathrm{x} 15 \mathrm{~cm})$ was attached to the rotating drum mandrel and $1.5 \mathrm{~mL}$ of the polymer solution was electrospun to build a layer of aligned nanofibres. The membrane coupon with nanofibres was then detached, replaced at 90 degrees to the original position and the solution was electrospun to form the next layer of aligned nanofibres. After repeating the procedure, the membrane coupon was heat-pressed at 110 ${ }^{\circ} \mathrm{C}$ using a heat roll laminator (J.Burrows) to stabilise its porous structure and produce the electrospun nanofibre supports in cross-hatched structures (CNF). The low temperature used during lamination is below the glass transition temperature of polysulfone and hence acts only to smooth the membrane surface rather than to melt the nanofibres. As a comparison, nanofibre supports in a random orientation (RNF) were prepared by the same conditions except for a drum rotation rate of $1.0 \mathrm{~m} / \mathrm{s}$ and solution injection volume of $9.0 \mathrm{~mL}$ were used without changing direction of the fibres during deposition. A random nanofibre support with a reduced thickness $60 \mu \mathrm{m}$ (RNF60) was also prepared using a solution injection vol- ume of 7.0 mL. The nanofibres were also prepared on aluminium foil. These nanofibres were detached from the foil to produce free-standing electrospun mats and these mats were used to characterise the physical properties of the electrospun structures, as described in the Characterisation section.

Nanocomposite membrane fabrication. The fabrication procedures for composite membranes formed with both CNF and RNF supports were identical. Prior to forming the PA layer, the surface of the nanofibre supports was modified by polydopamine to improve hydrophilicity. Dopamine $\left(2.0 \mathrm{~g} \mathrm{~L}^{-1}\right)$ was dissolved in Tris buffer $(50 \mathrm{~mL})$ prepared from Tris in purified water and adjusting the $\mathrm{pH}$ to 8.8 using dilute $\mathrm{HCl}$. Then, a nanofibre support was gently immersed into the dopamine solution for $1 \mathrm{~h}$ to allow polymerisation to occur. The support was then immersed in ethanol for 10 min to remove any unreacted polydopamine and then rinsed with purified water. ${ }^{30} \mathrm{~A}$ PA active layer was formed on the nanofibre supports by interfacial polymerisation as reported previously. ${ }^{12-13} 1.5 \mathrm{wt} \%$ of MPD was dissolved in purified water and $0.05 \mathrm{wt} \%$ of TMC was dissolved in n-hexane, respectively, and degassed by ultrasonication. A nanofibre support was held within a rubber gasket frame and binder clips, then MPD solution was poured into the frame for 5 mins. After draining the excess MPD solution and removing residual droplets by rolling a rubber roller across the surface, TMC solution was poured into the frame. After $1 \mathrm{~min}$ for interfacial polymerisation, the excess TMC solution was drained and the membrane surface was rinsed using $n$-hexane to wash residual reagents. The resulting membrane was dried in air at ambient conditions for 30 mins and immersed in purified water until use.

For comparison, TFC membranes were prepared using a conventional casting method followed by interfacial polymerisation. $20 \mathrm{wt} \%$ PSU solution in DMAc was prepared and cast onto polyester non-woven fabric using a doctor blade, then immediately immersed into purified water for phase inversion, resulting in an asymmetric PSU support layer. The PSU support was washed with purified water several times to remove residual solvent. After hydrophilic treatment by polydopamine, a PA layer was formed on the PSU support by interfacial polymerisation of MPD and TMC. An asymmetric membrane support was also prepared by phase inversion of the PSU solution on a glass plate for characterisation.

Characterisation. The morphology of the CNF supports, and their nanocomposite membranes were investigated with a scanning helium ion microscope (HIM, ORION NanoFab, Zeiss, Jena, Germany) and a scanning electron microscope (SEM, Teneo VolumeScope, FEI, Lausanne, Switzerland). The mechanical properties of the nanofibres, nanofibre supports, and composite membranes were measured using a universal testing machine (Instron, Norwood, MA) with five specimens of each sample prepared and tested according to ASTM D638-Type5 recommendations. Freestanding nanofibre layers were obtained from layers deposited onto aluminium foil and then peeled off. The porosity of the nanofibre and asymmetric supports was determined by filling the pores of a pre-weighed sample from five specimens using kerosene (see Supporting 
Information). The average pore sizes of the membrane supports were characterised by nitrogen gas permeation measurement (see Equation S2). ${ }^{31}$ Gas permeance of a membrane coupon with an area of $14.6 \mathrm{~cm}^{2}$ was measured using a bubble flow meter between 40 to $140 \mathrm{kPa}$. The maximum pore sizes were calculated by the Young-Laplace equation (Equation S3) from the breakthrough pressure of 20 wt\% 2-propanol aqueous solution. ${ }^{32} \mathrm{~A}$ membrane coupon was located in a modified dead-end stirred cell (HP4750, Sterlitech, Kent, WA) with 2-propanol solution and slowly pressurised. The pressure at which the first solution droplet was observed on the underside of the membrane was recorded as the breakthrough pressure. The contact angle with 2-propanol solution was measured using a contact angle goniometer (FTÅ200, First Ten Angstroms, Inc., Newark, CA). The diameter of the nanofibres were measured by five different HIM images using ImageJ software. The tortuosity $(\tau)$ was determined by the HagenPoiseuille equation (Equation S4) and the structural parameter (S) was determined by the relationship between membrane thickness, tortuosity, and porosity by Equation S5.7, 33

Reverse osmosis membrane performance. Water flux and salt rejection properties of CNF membranes were measured using both a high-pressure dead-end stirred cell (HP4750, Sterlitech, Kent, WA) and a crossflow RO system as previously described in Hoang et al. ${ }^{34}$ The dead-end cell was used to measure pure water permeability (PWP) of the membrane supports with an effective area of $14.6 \mathrm{~cm}^{2}$ at 1 bar and these measurements were used to determine the tortuosity of the membrane supports. Three specimens of each sample were used for data accuracy. The crossflow R0 system consisted of a Hydra-Cell G10 pump (Wanner Engineering, Minneapolis, MN), a $60 \mathrm{~L}$ feed tank and a crossflow cell unit (CF042, Sterlitech, Kent, WA). The membrane with an effective area of $42 \mathrm{~cm}^{2}$ was loaded into the RO testing cell and the feed solution was pressurised at between 5 to 55 bar. Purified water and both 2,000 ppm and 35,000 ppm $\mathrm{NaCl}$ aqueous solutions were used as feed. Three specimens of each sample were used for data accuracy, except for the extended time trial which used two specimens. The salt concentration of feed and permeate solutions was determined by a conductivity meter (SevenExcellence $^{\mathrm{TM}}$, Mettler Toledo, Columbus, $\mathrm{OH}$ ), to characterise membrane separation performance. To determine the membrane failure pressure, a membrane was loaded in the crossflow cell and the operating pressure was gradually increased and maintained at this pressure for at least 30 mins until the water flux stabilised. The water permeability coefficient (A) and $\mathrm{NaCl}$ permeability coefficient (B) were determined by the solution-diffusion model using Equations S6 and S7. Error margins were determined as \pm one standard deviation about the mean.

\section{RESULTS AND DISCUSSION}

Electrospinning onto a rotating drum collector was used to fabricate cross-hatched PSU nanofibres, by depositing alternating layers of orthogonally oriented aligned fibres. These structures were then used as CNF supports as described in Figure 1a. The PSU solution in a co-solvent of dimethylacetamide (DMAc) and tetrahydrofuran (THF) was used to generate aligned nanofibres by electrospinning on aluminium foil as well as the polyester non-woven fabric that is commonly used as a membrane substrate for water treatment membranes. ${ }^{13}$ We chose to work with PSU as it is commonly used in water treatment membranes to form a supporting layer through a phase inversion technique, ${ }^{8}$ implying that fibre structures produced from this material would be suitable for subsequent membrane applications.

The architecture of fibrous electrospun structures (fibre thickness, porosity, mat thickness, etc.) depends on a variety of processing parameters including polymer type and molecular weight, selection of solvent, applied voltage, solution flow rate, and geometry of the collector. In this work, we found that solution composition greatly affected nanofibre thickness and regularity, while the rotating speed of the drum determined nanofibre alignment. To create the crosshatched structures, the foil or the nonwoven fabric onto which the aligned nanofibres were deposited was detached from the drum mandrel and replaced at 90 degrees to the original position and another layer of nanofibres was deposited. Other CNF structures were formed by repeating the procedure. These structures are referred to as CNF\#, where \# means the total number of nanofibre layers (e.g. CNF4 has two pairs of alternating layers, 4 layers in total). The cross-hatched structures act as a support for fabrication of the active layer. Additionally, this novel structure provides greater mechanical strength and porosity as compared with conventional asymmetric supports composed by phase inversion (Figure $1 b, c)$.

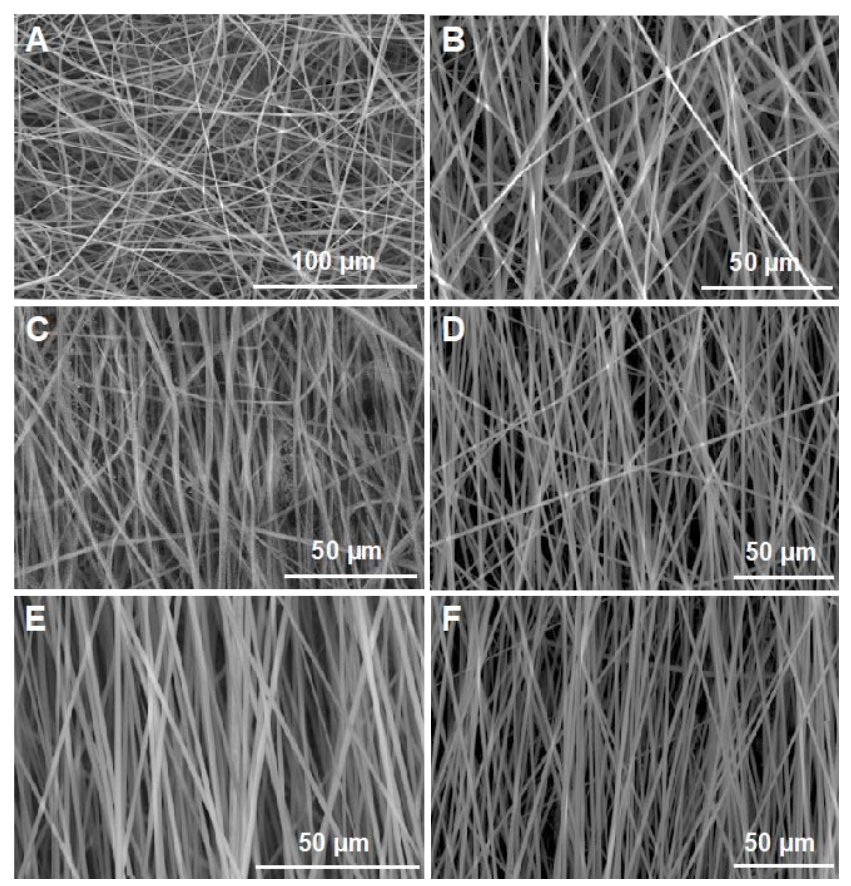

Figure 2. HIM images of PSU nanofibres fabricated on a rotating drum collector at (a) $1.6 \mathrm{~m} / \mathrm{s}$, (b) $3.9 \mathrm{~m} / \mathrm{s}$, (c) $7.9 \mathrm{~m} / \mathrm{s}$, (d) $10 \mathrm{~m} / \mathrm{s}$, (e) $13 \mathrm{~m} / \mathrm{s}$, and (f) $16 \mathrm{~m} / \mathrm{s}$.

As described in Figure 2, the rotating speed of the collector was a significant factor in determining nanofibre alignment. Randomly oriented nanofibres were observed when the surface speed of the rotating collector was 1.6 
$\mathrm{m} / \mathrm{s}$; partially aligned nanofibres were formed between 3.9 and $10 \mathrm{~m} / \mathrm{s}$; while nanofibres were well aligned at rotation speeds higher than $13 \mathrm{~m} / \mathrm{s}$. The average diameter for randomly oriented fibres were $700 \pm 20 \mathrm{~nm}$ and $650 \pm 20 \mathrm{~nm}$ for aligned nanofibres (Figure S1).

After confirming the desired microporous structure of fibres with nanometre scale thickness and pore size, the nanofibre membrane support was heat-pressed using a roll laminator. Characteristics of the nanofibre supports after this heat pressing step are summarised in Table 1, compared with asymmetric supports prepared by phase inversion. Thickness, pore size, PWP, tortuosity and the structural parameter were characterised for the nanofibre and asymmetric supports prepared on the non-woven fabric, but excluding the fabric in the data analysis. The thickness of these supports were measured from their crosssectional scanning helium ion microscope (HIM) images. Porosity was determined for nanofibres prepared on aluminium foil since the non-woven fabric was able to soak a large volume of liquid, leading to inaccuracy when this weight-based measurement was applied. Freestanding asymmetric membrane supports were also prepared by phase inversion on a glass plate for their porosity measurement.

The thickness of the CNFs was dependent on the volume of solution deposited during electrospinning, as it increased from $15 \mu \mathrm{m}$ for CNF2 to $60 \mu \mathrm{m}$ for CNF7. The thickness of the RNFs were adjusted to be similar to CNF7. However, an asymmetric support of at least $120 \mu \mathrm{m}$ was needed to ensure a uniform layer could be provided over the uneven surface of the non-woven fabric. The porosity of the CNFs reduced as more alternating layers were de- posited from $78 \%$ for CNF2 to $70 \%$ for CNF7, but the high porosity of CNF2 was due to the low packing density of the nanofibres in only two layers.

CNFs presented lower porosity than RNFs because the tightly aligned nanofibres reduced their porosity. Random nanofibres generally form an irregular structure with larger space between nanofibres, whereas gaps between aligned nanofibers are relatively small because the aligned nanofibers can sit closer together. However, both CNF and RNF nanofibres demonstrated a similar average pore size of around $0.33 \mu \mathrm{m}$ (Figure S2, Table S1). The porosity and pore size of the asymmetric support was much smaller than for the nanofibre supports $(56 \%$ and $0.19 \mu \mathrm{m})$ which is likely to enhance its mechanical strength but reduce water permeability. Maximum pore sizes were obtained from the contact angle and breakthrough pressure of the nanofibre supports using $20 \mathrm{wt} \%$ 2-propanol solution (Table S2). The maximum pore sizes were only slightly larger than the average pore sizes, meaning that the nanofibre supports have relatively narrow pore size distributions. Despite similar porosity and pore sizes in CNFs and RNF, the PWPs of CNFs were much higher than that of RNF supports, measured at 1 bar using a dead-end filtration cell. The PWP of CNFs was in the range of 11,000 to $20,200 \mathrm{~L} \mathrm{~m}^{-}$ ${ }^{2} \mathrm{~h}^{-1}$ bar $^{-1}$ depending of the number of alternating layers, significantly higher than that of the RNF $\left(7,610 \mathrm{~L} \mathrm{~m}^{-2} \mathrm{~h}^{-1}\right.$ bar $\left.^{-1}\right)$, RNF60 $\left(8,630 \mathrm{~L} \mathrm{~m}^{-2} \mathrm{~h}^{-1}\right.$ bar $\left.^{-1}\right)$ and the asymmetric

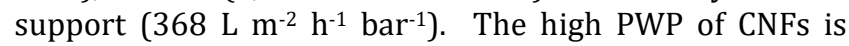
mainly from the reduced membrane tortuosity $(\tau)$. Note that the PWP of CNF2 was immeasurable due to its low thickness and porosity.

Table 1. Characteristics of the nanofibre supports.

\begin{tabular}{|c|c|c|c|c|c|c|}
\hline & $\begin{array}{c}\text { Thickness } \\
(\mu \mathrm{m})\end{array}$ & $\begin{array}{c}\text { Porosity } \\
\text { (\%) }\end{array}$ & $\begin{array}{c}\text { Pore size } \\
(\mu \mathrm{m})\end{array}$ & $\begin{array}{c}\text { Tortuosity, } \\
\tau(-)\end{array}$ & $\mathrm{S}(\mu \mathrm{m})$ & $\begin{array}{c}\mathrm{PWP} \\
\left(\mathrm{L} \mathrm{m}^{-2} \mathrm{~h}^{-1} \text { bar }^{-1}\right)\end{array}$ \\
\hline RNF & $75 \pm 2$ & $74 \pm 2$ & 0.33 & 1.61 & 164 & $7,610 \pm 100$ \\
\hline RNF60 & $59 \pm 1$ & $72 \pm 1$ & 0.34 & 1.89 & 155 & $8,630 \pm 70$ \\
\hline CNF2 & $15 \pm 1$ & $78 \pm 2$ & 0.44 & - & - & - \\
\hline CNF3 & $23 \pm 2$ & $73 \pm 5$ & 0.30 & 1.54 & 48 & $20,200 \pm 70$ \\
\hline CNF4 & $31 \pm 1$ & $71 \pm 4$ & 0.28 & 1.31 & 57 & $15,300 \pm 100$ \\
\hline CNF5 & $42 \pm 3$ & $70 \pm 2$ & 0.30 & 1.30 & 77 & $12,700 \pm 90$ \\
\hline CNF6 & $53 \pm 2$ & $70 \pm 3$ & 0.32 & 1.32 & 101 & $11,500 \pm 80$ \\
\hline CNF7 & $60 \pm 2$ & $70 \pm 2$ & 0.34 & 1.37 & 117 & $11,000 \pm 90$ \\
\hline Asymmetric support & $120 \pm 30$ & $56 \pm 4$ & 0.19 & 5.33 & 1137 & $368 \pm 10$ \\
\hline PAN nanofibre $^{1}$ & $200 \pm 15$ & $66 \pm 1$ & 0.60 & 1.62 & - & $7,950 \pm 50$ \\
\hline PES nanofibre $^{7}$ & $50 \pm 8$ & $83 \pm 1$ & - & 1.33 & $80 \pm 6$ & $1139 \pm 45$ \\
\hline Asymmetric PAN 1 & $186 \pm 15$ & $60 \pm 1$ & 0.33 & 6.86 & - & $586 \pm 50$ \\
\hline
\end{tabular}


The tortuosity often describes fluid flow through porous media and is another indicator of membrane resistance (see Equation S4). The water flux through both asymmetric supports with a sponge-like structure and nanofibrous supports with interconnected pore structures can be used to determine the tortuosity via the Hagen Poiseuille equation (Equation S4) ${ }^{33}$ The tortuosity of the RNF60 calculated in this manner was 1.89 and that of the RNF was 1.61 which is similar to other random nanofibre supports prepared by electrospinning, such as PAN with a tortuosity of 1.62 and polyethersulfone (PES) with a tortuosity of $1.33 .{ }^{1}$, 7 These values are much smaller than that determined for the asymmetric support (5.33). A tortuosity of 1.00 implies uniform parallel cylindrical pores orthogonal to the membrane surface, ${ }^{33}$ and so these nanofibre membranes exhibit tortuosity close to theoretical limits. However, standard electrospinning methods deposit nanofibres in a random orientation resulting in an intrinsically tortuous manner despite having low tortuosity values. Cross-hatched structures from aligned electrospun nanofibres create channels for unimpeded water flow with even lower tortuosity in a range of 1.30 to 1.54 . Although more layers of aligned nanofibres were deposited and the membrane became thicker, the membrane tortuosity remained almost constant because of the regular inter-fibre spacing. The structural parameter (S) is similarly related to the Hagen Poiseuille equation and represents the relationship between the membrane tortuosity, thickness, and the porosity (Equation S5) that dictates the overall membrane resistance. ${ }^{33,35-}$ 37 The $\mathrm{S}$ value is inversely proportional to thickness, so increases for the CNFs from $48 \mu \mathrm{m}$ (CNF3) to $117 \mu \mathrm{m}$ (CNF7). However, when comparing CNF7 and the RNF of a similar thickness, the $S$ value of the RNF is nearly 1.5 fold $(164 \mu \mathrm{m})$, indicating that the cross-hatched structure is advantageous in reducing the membrane resistance. In RO membrane processes, solute diffusion on the permeate side has little effect on water flux, but it can result in significant flux decline in processes when an osmotic pressure is applied on this side, such as forward osmosis and pressure retarded osmosis, ${ }^{36}$ meaning that CNF membranes would bring significant improvement when applied to such processes.

Cross-hatched nanofibre structures were clearly observed in the HIM image of Figure 3a which was prepared by depositing a small volume of solution onto aluminium foil. However, there is only one layer of aligned fibres visible in the CNF supports, with the second layer not visible due to the limited depth of field (Figure 3b). The PA active layers on these supports were fabricated by interfacial polymerisation. Incompatibility between the hydrophobic PSU nanofibres and hydrophilic PA could potentially cause delamination of the PA active layer after formation. Spray coating of the PSU with a hydrophilic substance such as poly(vinyl alcohol) can be used to reduce such delamination and to increase adhesion between the polymers. ${ }^{38-39}$ In the present case, we selected a mussel-inspired polydopamine coating, which is known to improve hydrophilicity without changing the microstructure, although the complex polymerisation mechanism is undefined. ${ }^{30}$ The nanofibrous structures of the CNF supports were unchanged by this polydopamine coating due to its very thin and uniform nature as shown in Figure S3.
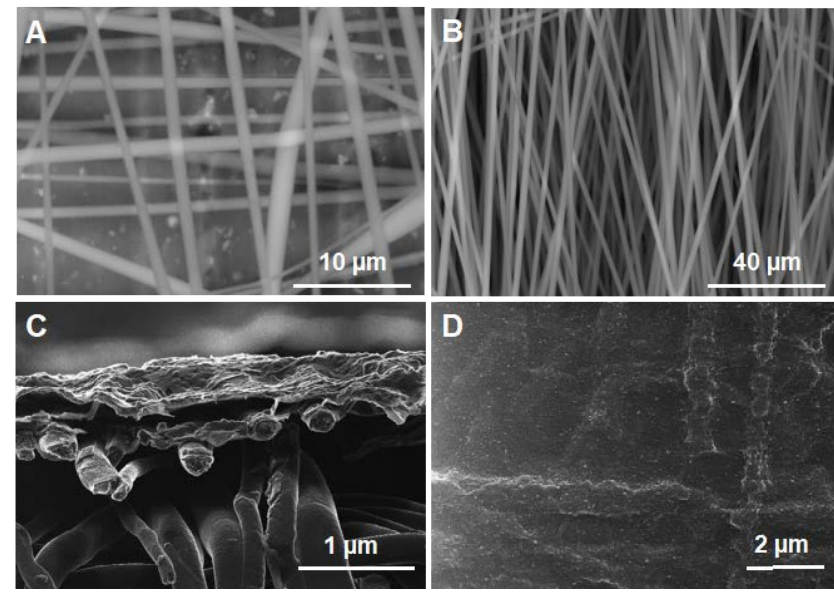

Figure 3. HIM images of (a) nanofibres in cross-hatched structures, (b) surface of CNF supports, (c) cross-section and (d) surface of CNF composite membranes.

The improved hydrophilicity facilitated interfacial polymerisation of PA on the hydrophobic PSU surface. The ultrathin layer of PA after interfacial polymerisation on CNFs was defect-free with good adhesion to the CNFs, as shown in Figure 3c, d. The thickness of the PA layer was observed to be around $200 \mathrm{~nm}$, but the actual thickness is difficult to measure due to its typical ridge-and-valley structure that enlarges surface area and reduces active layer thickness. ${ }^{40-41}$ Interfacial polymerisation also formed a PA layer on the RNFs of similar thickness, as presented in Figure S4. The nanofibrous structures of the CNF membranes with a PA layer were retained even after high pressure RO operation.

Electrospinning has been applied previously to produce membrane supports that are very highly porous to minimise impedance to flow but still provide the necessary mechanical strength. ${ }^{42-44}$ However, the relatively weak mechanical properties of electrospun nanofibres limits their use to relatively low pressure membrane processes and hinder their application to high pressure membrane processes, such as RO. Typical electrospun membranes have randomly oriented nanofibres. In the present work, fibre alignment during electrospinning has allowed the production of cross-hatched nanofibre structures where the thickness and mechanical properties of the nanofibre layers are controlled by a number of alternating layers. The novel nanofibre composite membrane improves mechanical properties, enabling the use of these structures in high hydraulic pressure conditions for the first time. Further, the improved mechanical properties would likely reduce membrane damage during manual handling, reducing operating costs. ${ }^{45}$ 


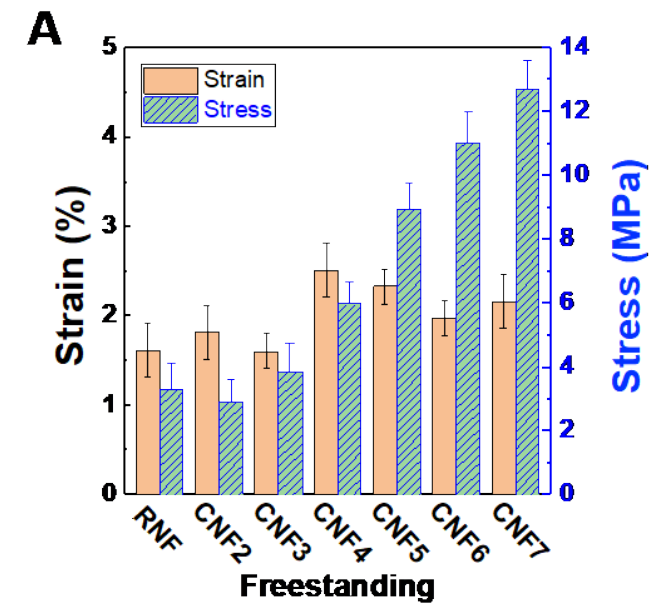

B

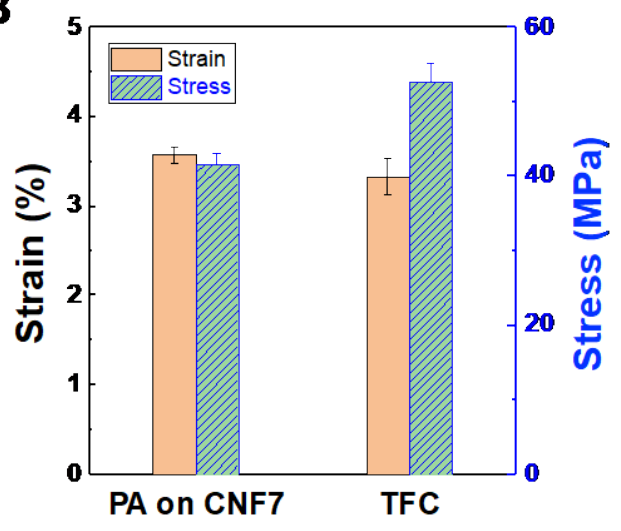

Figure 4. Mechanical properties of (a) the freestanding nanofibres (b) the composite membranes.

Figure 4 shows the mechanical properties of nanofibres and the composite membranes as the average tensile strength and elongation at break, determined from the stress-strain curve provided in Figure S5. Nanofibres in both random orientations and cross-hatched structures were prepared on aluminium foil and peeled off as freestanding samples. Comparing CNFs with RNFs, the crosshatched structure greatly improved the tensile strength while elongation is similar at around $2 \%$ due to the rigid molecular structure of PSU. The tensile strength of the CNFs was proportional to the number of layers, increasing from 2.9 MPa for CNF2 to $13 \mathrm{MPa}$ for CNF7. These crosshatched structures greatly improved the mechanical properties because a significantly larger number of the fibres were in the direction of the applied load, resulting in a larger cross sectional area to support the load. The tensile strength of the CNF composite and conventional TFC membranes was much higher than that of the freestanding nanofibres because the main mechanical strength comes from the non-woven fabric substrate. However, the underlying mechanical strength of the support layers is essential since the ultrathin PA active layer relies on the resilience of this support layer.
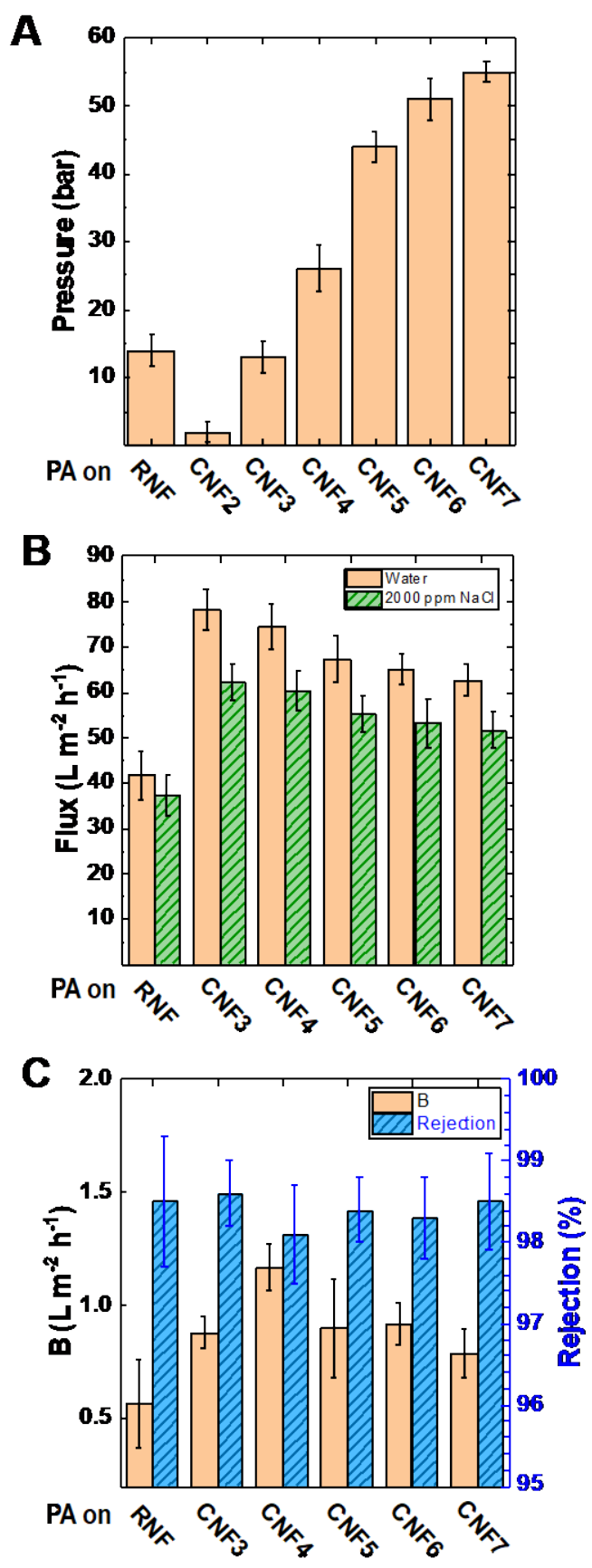

Figure 5. Effects of the number of layers deposited on the (a) membrane failure pressure, (b) water flux, and (c) $\mathrm{NaCl}$ permeability coefficient (B) and rejection, measured at 10 bar.

The RO performance of the nanofibre membranes was investigated by a crossflow RO system using both purified water and a 2,000 ppm $\mathrm{NaCl}$ aqueous solution for water flux and salt separation properties. Effective RO membranes should withstand the operating hydraulic pressure, while membranes which are not designed for high pressure operation fail as indicated by a sudden or gradual water flux increase as cracks emerge in the active layer. In the present study, the membrane failure pressure was defined as the pressure where such a sudden flux increase was observed, as described in Figure $5 \mathrm{a}$. The RNF membrane failed at around 14 bar, consistent with the mechan- 
ical strength of RNF nanofibres shown in Figure 4a and would not be suitable for high pressure RO process. The CNF membranes were able to resist hydraulic pressures of up to 55 bar for CNF7, suitable for SWRO. The CNF2 membrane burst only at 2 bar, meaning that 2 layers of aligned fibres in orthogonal positions do not provide enough strength, but the membrane failure pressure for CNF3 increased to 13 bar.

Membrane permeation and separation properties were measured at 10 bar using a crossflow cell, shown in Figure $5 \mathrm{~b}, \mathrm{c}$ as a function of the number of aligned fibre layers deposited. The membranes demonstrated a higher flux for pure water than for $2000 \mathrm{ppm} \mathrm{NaCl}$ solution due to the osmotic pressure difference. The pure water flux for the RNF membrane was $42 \pm 6 \mathrm{~L} \mathrm{~m}^{-2} \mathrm{~h}^{-1}$, whereas that of the CNF membranes was around $150-180 \%$ higher in the range of 63 to $78 \mathrm{~L} \mathrm{~m}^{-2} \mathrm{~h}^{-1}$. The increased water flux of the CNF membranes was mainly from the reduced tortuosity, given the porosity and pore sizes were smaller than for the RNFs. The $\mathrm{NaCl}$ rejection is around $98 \%$ for all nanofibre membranes as the salt permeability is predominantly an intrinsic property of the active PA layer. The value is lower than that of commercial RO membranes, which can be over $99.7 \%$. In industrial practice the properties of the PA layer are optimised using surfactants and other additives to achieve greater rejection. Further, a polyvinyl alcohol layer is often applied on top of the PA to reduce the impact of defects in this layer upon the rejection performance. ${ }^{46}$

The $\mathrm{NaCl}$ permeability (B value) is a more subtle parameter and indicates a slightly higher value for the CNF membranes ( 0.8 to $\left.1.2 \mathrm{~L} \mathrm{~m}^{-2} \mathrm{~h}^{-1}\right)$ relative to that of the RNF membranes $0.6 \mathrm{~L} \mathrm{~m}^{-2} \mathrm{~h}^{-1}$. However, it should be noted that both these parameters are influenced by the water flux. That is, as the water flux increases for the CNF membranes, it increases the convective flow of salt leading to a higher salt permeability ${ }^{47}$ Conversely, the higher water flux dilutes the permeate concentration, which can counteract this effect in the calculation of the rejection parameter.

We selected the CNF4 membrane to investigate the pressure effects on membrane performance based on its balance of high water flux and moderate failure pressure. Water flux, saltwater flux and separation properties were measured from 5 to 20 bar using a crossflow cell as shown in Figure 6. The performance of the RNF membranes was measured only up to $13 \mathrm{bar}$ as failure occurred at this pressure. The CNF4 membrane presented the highest water flux across the entire pressure range; $170 \%$ and $230 \%$ of that for the RNF and TFC membranes, respectively. As expected, the water flux gradually increased as a function of applied hydraulic pressure and the salt water flux was slightly lower due to the osmotic pressure. Extrapolation of the pure water flux curves indicated a non-zero intercept, suggesting that some membrane compaction occurred in all cases, as commonly observed in PA membranes. ${ }^{48-49}$ The membranes presented around $98 \% \mathrm{NaCl}$ rejection regardless of the support layer structures since the PA active layers were prepared under the same conditions. Conversely, as discussed above, the $\mathrm{NaCl}$ permeability coefficient increased when high pressure was applied, because of the increased water flux providing for a greater convective flow.
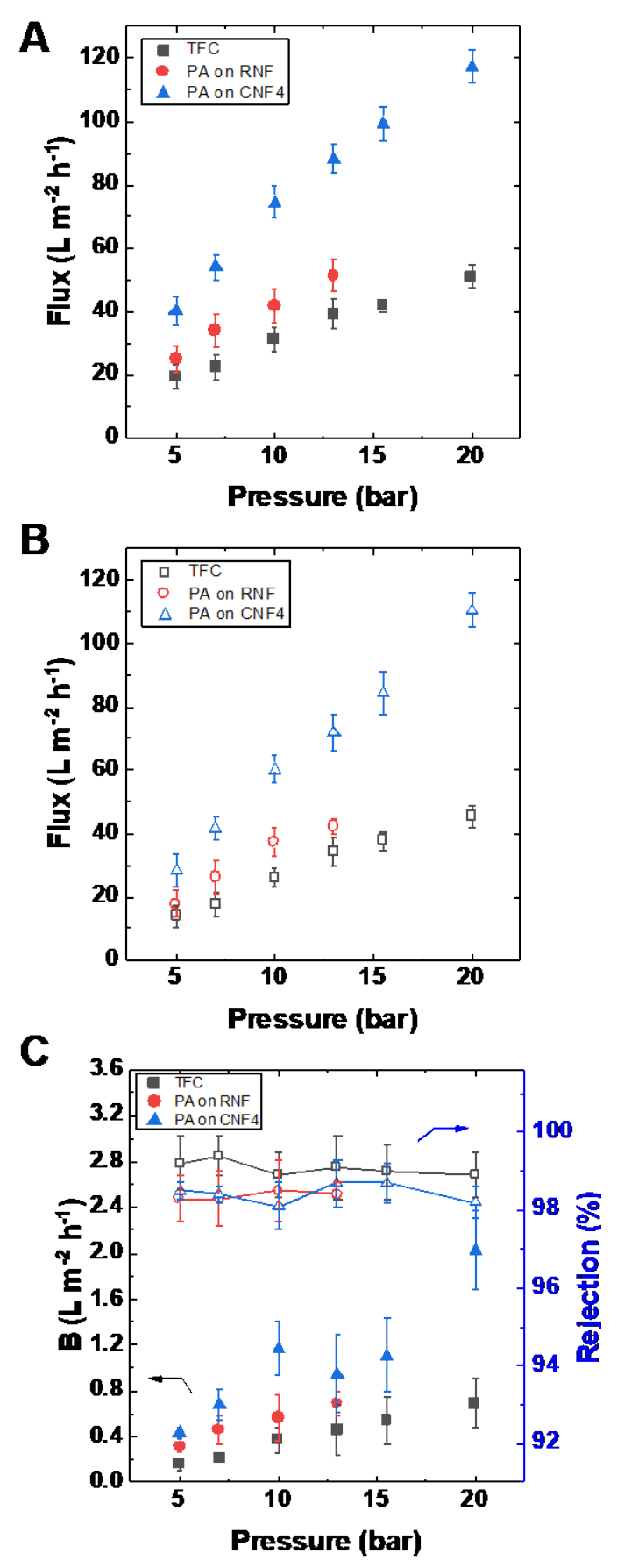

Figure 6. (a) Pure water flux, (b) salt water flux, and (c) $\mathrm{NaCl}$ permeability coefficients of random nanofibre (RNF) and crosshatched nanofibre (CNF) membranes versus conventional TFC membranes. 

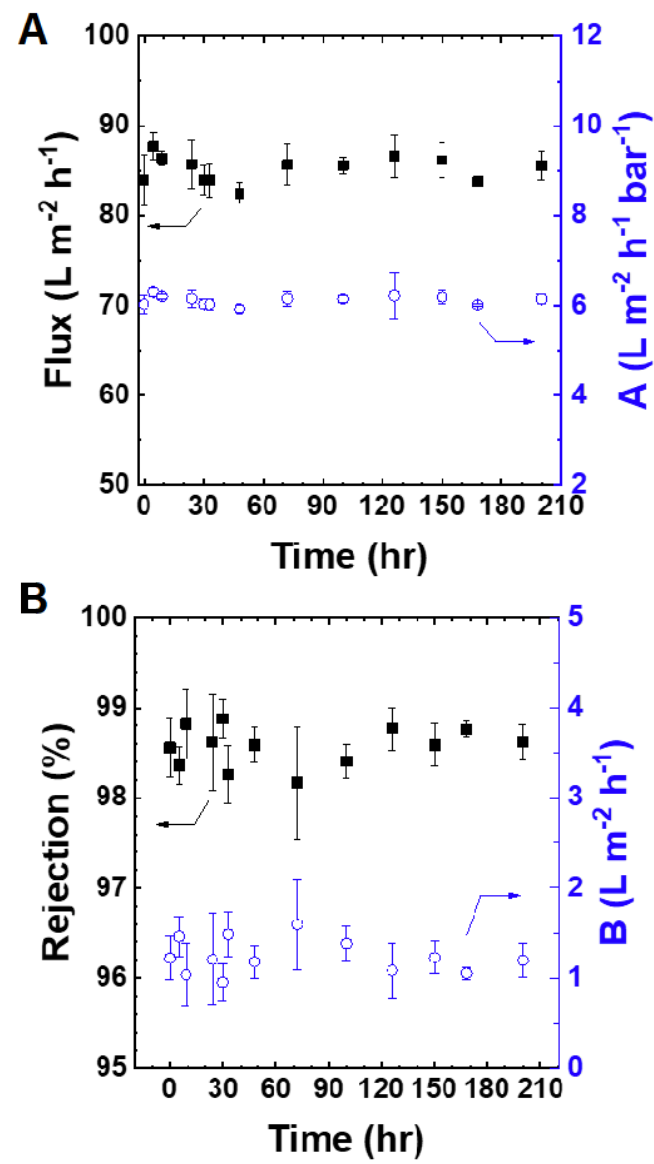

Figure 7. (a) Salt water flux, water permeability coefficient, A, (b) salt rejection, and solute permeability coefficient, B of CNF4 membrane for extended operation with 2,000 ppm $\mathrm{NaCl}$ solution at 15.5 bar.

In seawater desalination, a high hydraulic pressure is applied to overcome the osmotic pressure of seawater. ${ }^{8}$ To evaluate the RO performance of CNF membranes at such high pressures, CNF7 was tested and compared with CNF4 as summarised in Table 2 . Feed solutions with $\mathrm{NaCl}$ in $2,000 \mathrm{ppm}$ as simulated brackish water and 35,000 ppm as simulated seawater $\mathrm{NaCl}$ were used to replicate medium pressure (10 and 20 bar) and high pressure (35 and 55 bar) operations, respectively. The greater flux of CNF4 than CNF7 at the same pressure is consistent to the result in Figure $5 \mathrm{~b}$ due to the greater flow resistance from thicker supporting layers. The flux of RO membranes depends on the water permeability coefficient (A), the applied hydraulic pressure $(\Delta \mathrm{P})$ and the osmotic pressure $(\Delta \pi)$ of the feed solution as shown in Equation S4.33 After accounting for the differences in $\Delta \mathrm{P}$ and $\Delta \pi$ the CNF4 and CNF7 membranes demonstrated consistent water permeability coefficients of $5.8 \pm 0.6$ and $6.6 \pm 0.9 \pm 0.8 \mathrm{~L} \mathrm{~m}^{-2} \mathrm{~h}^{-1} \mathrm{bar}^{-1}$. Both CNF4 and CNF7 membranes exhibited similar $\mathrm{NaCl}$ rejection and solute permeability coefficients (B) as these parameters mainly depend upon the PA active layers. Figure 7 shows the performance stability in water flux and salt rejection for the CNF4 membrane with 2,000 ppm $\mathrm{NaCl}$ solution at 15.5 bar. The membrane presented almost constant water flux and salt rejection for $200 \mathrm{hr}$ of continuous operation.
Table 2. Performance of crosshatched nanofibre (CNF) membranes during reverse osmosis operation.

\begin{tabular}{|c|c|c|c|c|c|c|}
\hline \multirow[b]{2}{*}{$\begin{array}{l}\text { Applied hydraulic } \\
\text { pressure (bar) }\end{array}$} & \multicolumn{4}{|l|}{ CNF7 } & \multicolumn{2}{|l|}{ CNF4 } \\
\hline & 10 & 20 & 35 & 55 & 10 & 20 \\
\hline $\begin{array}{l}\text { Feed } \mathrm{NaCl} \text { concen- } \\
\text { tration }(\mathrm{ppm})\end{array}$ & 2,000 & $\begin{array}{l}2,00 \\
0\end{array}$ & $\begin{array}{l}35,0 \\
00\end{array}$ & $\begin{array}{l}35,0 \\
00\end{array}$ & $\begin{array}{l}2,00 \\
0\end{array}$ & $\begin{array}{l}2,00 \\
0\end{array}$ \\
\hline $\begin{array}{lr}\text { Feed } & \text { solution } \\
\text { osmotic } & \text { pressure } \\
\text { (bar) } & \end{array}$ & 1.6 & 1.6 & 27.6 & 27.6 & 1.6 & 1.6 \\
\hline Flux $\left(\mathrm{L} \mathrm{m}^{-2} \mathrm{~h}^{-1}\right)$ & $\begin{array}{ll}51 \pm \\
2\end{array}$ & $\begin{array}{l}101 \\
\pm 6\end{array}$ & $\begin{array}{l}46 \pm \\
3\end{array}$ & $\begin{array}{l}115 \\
\pm 4\end{array}$ & $\begin{array}{l}61 \pm \\
3\end{array}$ & $\begin{array}{l}110 \\
\pm 6\end{array}$ \\
\hline $\begin{array}{l}\text { Water permeabil- } \\
\text { ity coefficient, A } \\
\left(\mathrm{L} \mathrm{m}^{-2} \mathrm{~h}^{-1} \text { bar- }^{-1}\right)\end{array}$ & $\begin{array}{l}6.1 \pm \\
0.2\end{array}$ & $\begin{array}{l}5.5 \pm \\
0.4\end{array}$ & $\begin{array}{l}6.3 \pm \\
0.4\end{array}$ & $\begin{array}{l}5.1 \pm \\
0.2\end{array}$ & $\begin{array}{l}7.2 \pm \\
0.4\end{array}$ & $\begin{array}{l}6.0 \pm \\
0.3\end{array}$ \\
\hline $\mathrm{NaCl}$ rejection (\%) & $\begin{array}{l}98.5 \\
\pm 0.3\end{array}$ & $\begin{array}{l}98.7 \\
\pm 0.1\end{array}$ & $\begin{array}{l}98.5 \\
\pm 0.4\end{array}$ & $\begin{array}{l}98.4 \\
\pm 0.6\end{array}$ & $\begin{array}{l}98.0 \\
\pm 0.4\end{array}$ & $\begin{array}{l}98.2 \\
\pm 0.5\end{array}$ \\
\hline $\begin{array}{l}\text { Solute permeabil- } \\
\text { ity coefficient, B } \\
\left(\mathrm{L} \mathrm{m}^{-2} \mathrm{~h}^{-1}\right)\end{array}$ & $\begin{array}{l}0.79 \\
\pm 0.1\end{array}$ & $\begin{array}{l}1.3 \pm \\
0.03\end{array}$ & $\begin{array}{l}0.70 \\
\pm 0.2\end{array}$ & $\begin{array}{l}1.9 \pm \\
0.8\end{array}$ & $\begin{array}{l}1.2 \pm \\
0.3\end{array}$ & $\begin{array}{l}2.0 \pm \\
0.6\end{array}$ \\
\hline
\end{tabular}
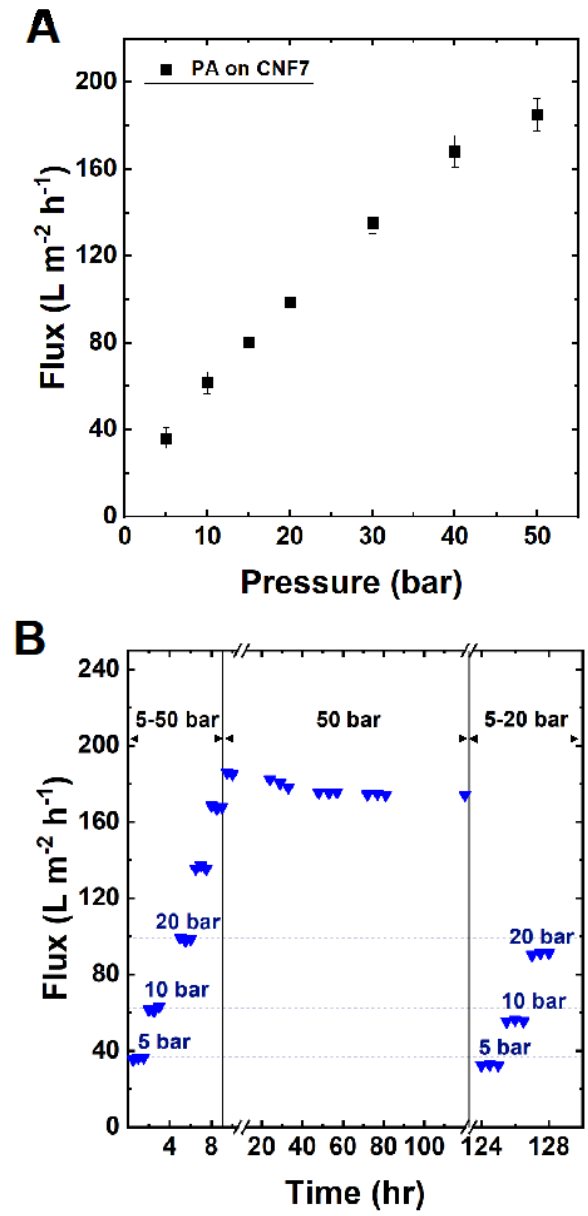

Figure 8. Pure water flux of CNF7 membrane (a) at elevated pressures and (b) by interval measurement after operation at 50 bar.

Sustained operation at high pressure is known to compress many membrane support structures leading to reduced performance. To assess the extent of such compac- 
tion in the present case, the CNF7 membrane was exposed to high pressures during water flux measurements (Figure 8). The water flux increased linearly with pressure up to 40 bar, but the water flux at 50 bar was slightly lower than expected. A similar trend was observed after $100 \mathrm{~h}$ of continuous operation at 50 bar. The water flux decreased from 186 to $174 \mathrm{~L} \mathrm{~m}^{-2} \mathrm{~h}^{-1}$ bar-1 $^{-1}$ within the first $30 \mathrm{~h}$ but was then stable. When the membrane was then exposed to lower pressures between 5 to 20 bar, there was some reduction in flux relative to the original values, but the reduction was only minor.

Recently, the upper bound of a trade-off relationship between the water permeability coefficient (A) and the ratio of this water permeability coefficient and the $\mathrm{NaCl}$ permeability coefficient (A/B) as a selectivity factor has been established to evaluate the performance of TFC water treatment membranes. ${ }^{50}$ Although PA based TFC membranes generally have the same or similar chemical structures, their performance varies depending upon the membrane fabrication technique. Usually commercial TFC membranes with ultrathin PA layers prepared by a controlled fabrication process exhibit performance close to the upper bound, but PA membranes prepared at lab-scale presented lower water permeability due to their relatively thick active layers and the influence of concentration polarisation in lab-scale systems. ${ }^{50}$ Figure 8 presents the RO performance of the membranes in this study on the upper bound plot as a comparison with other RO membranes in the literature. The TFC membranes on an asymmetric support present moderate water permeability and $\mathrm{NaCl}$ selectivity similar to the performance of other laboratory prepared TFC membranes. The water permeability of the RNF membranes is higher than that of TFC membranes, but CNF membranes showed even higher water permeability, close to the upper bound, although $\mathrm{NaCl}$ separation performance was retained. Note that most RO membranes in Figure 8 were prepared on asymmetric supports with the research effort focused on improving the properties of the active layers, meaning that introduction of a cross-hatched structure would great improve their performance, exceeding the upper bound.

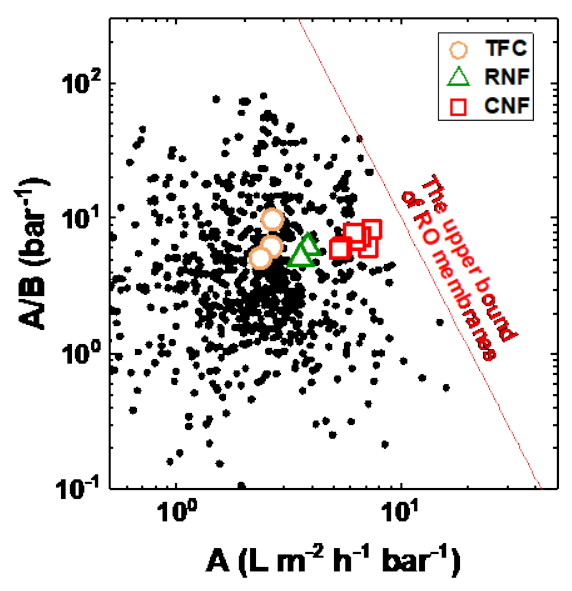

Figure 9. The permeance-selectivity trade-off for nanofibre composite membranes in the correlation between water $/ \mathrm{NaCl}$ selectivity and water permeability coefficient.

\section{CONCLUSIONS}

In summary, cross-hatched nanofibrous support structures and nanofibre composite membranes were successfully fabricated using electrospinning of PSU nanofibres, followed by PA interfacial polymerisation. Our approach to increase water permeability of RO membranes has focussed on reducing the resistance to water flows of the membrane support layer, by preparing a structure with high porosity and reduced tortuosity, while improving mechanical strength. We have demonstrated fibre alignment during electrospinning of the polymer solution on a rotating mandrel. This fibre alignment has allowed us to then produce cross-hatched nanofibre structures by depositing alternating layers of aligned nanofibres in orthogonal directions. The novel nanofibre composite membrane with a PA layer on top of these CNF supports presented increased water flux and comparable salt rejection when compared to a conventional TFC membrane and improved mechanical properties under high hydraulic pressures when compared to a typical electrospun membrane.

This development of next generation membranes for water treatment can be rapidly applied to current industrial processes in membrane manufacturing. The membrane preparation method uses existing technology that is capable today of producing up to $5000 \mathrm{~m}^{2}$ /day of electrospun support material. ${ }^{51}$ For aligned nanofibres, constant rotation is required, but the rotation velocity of around $13 \mathrm{~m} / \mathrm{s}$ is readily achievable. Other alignment techniques, such as using conductive wires are also possible. ${ }^{52}$ Moreover, the manufactured membrane can be readily installed in existing desalination plants as it uses the same polymers as currently deployed. The membrane fabrication technique for cross-hatched nanofibre structures can be a platform for various other membrane processes such as nanofiltration, membrane distillation, forward osmosis, pressure retarded osmosis or carbon dioxide stripping by improving the membrane permeability.

\section{ASSOCIATED CONTENT}

Supporting Information. The Supporting Information is available free of charge via the Internet at http://pubs.acs.org. Average diameter of nanofibres; HIM images of nanofibres before and after polydopamine coating; Membrane mechanical properties.

\section{AUTHOR INFORMATION}

\section{Corresponding Author}

* Professor S. E. Kentish - Department of Chemical Engineering, The University of Melbourne, Parkville, VIC 3010, Australia; E-mail: sandraek@unimelb.edu.au

\section{ACKNOWLEDGMENT}

This research was supported under the Australian Research Council Discovery Projects Scheme (Project number DP190102253). The authors acknowledge the staff of the Materials Characterisation and Fabrication Platform (MCFP) at the University of Melbourne, the Advanced Microscopy Facility at Bio21 Institute and the Victorian Node of the Australian National Fabrication Facility (ANFF) for their technical assistance. 


\section{REFERENCES}

(1) Lu, T.-D.; Chen, B.-Z.; Wang, J.; Jia, T.-Z.; Cao, X.-L.; Wang, Y.; Xing, W.; Lau, C. H.; Sun, S.-P. Electrospun nanofiber substrates that enhance polar solvent separation from organic compounds in thin-film composites. J. Mater. Chem. A 2018, 6 (31), 1504715056.

(2) Warsinger, D. M.; Chakraborty, S.; Tow, E. W.; Plumlee, M. H.; Bellona, C.; Loutatidou, S.; Karimi, L.; Mikelonis, A. M.; Achilli, A.; Ghassemi, A.; Padhye, L. P.; Snyder, S. A.; Curcio, S.; Vecitis, C. D.; Arafat, H. A.; Lienhard, J. H. A review of polymeric membranes and processes for potable water reuse. Prog. Polymr. Sci. 2018, 81, 209-237.

(3) McGilvery, C. M.; Abellan, P.; Kłosowski, M. M.; Livingston, A G.; Cabral, J. T.; Ramasse, Q. M.; Porter, A. E. Nanoscale Chemical Heterogeneity in Aromatic Polyamide Membranes for Reverse Osmosis Applications. ACS Applied Materials \& Interfaces 2020, 12 (17), 19890-19902.

(4) Ray, J. R.; Tadepalli, S.; Nergiz, S. Z.; Liu, K.-K.; You, L.; Tang Y.; Singamaneni, S.; Jun, Y.-S. Hydrophilic, Bactericidal Nanoheater-Enabled Reverse Osmosis Membranes to Improve Fouling Resistance. ACS Applied Materials \& Interfaces 2015, 7 (21), 11117-11126.

(5) Huang, H.; Lin, S.; Zhang, L.; Hou, L. a. Chlorine-Resistant Polyamide Reverse Osmosis Membrane with Monitorable and Regenerative Sacrificial Layers. ACS Applied Materials \& Interfaces 2017, 9 (11), 10214-10223.

(6) Kim, S.; Ou, R.; Hu, Y.; Li, X.; Zhang, H.; Simon, G. P.; Wang, H. Non-swelling graphene oxide-polymer nanocomposite membrane for reverse osmosis desalination. J. Membr. Sci. 2018, 562, 47-55.

(7) Song, X.; Liu, Z.; Sun, D. D. Nano gives the answer: breaking the bottleneck of internal concentration polarization with a nanofiber composite forward osmosis membrane for a high water production rate. Adv. Mater. 2011, 23 (29), 3256-3260.

(8) Li, D.; Yan, Y.; Wang, H. Recent advances in polymer and polymer composite membranes for reverse and forward osmosis processes. Prog. Polymr. Sci. 2016, 61, 104-155.

(9) Elimelech, M.; Phillip, W. A. The future of seawater desalination: energy, technology, and the environment. Science 2011, 333 (6043), 712-717.

(10) Alsarayreh, A. A.; Al-Obaidi, M. A.; Al-Hroub, A. M.; Patel, R.; Mujtaba, I. M. Evaluation and minimisation of energy consumption in a medium-scale reverse osmosis brackish water desalination plant. Journal of Cleaner Production 2020, 248, 119220.

(11) Pan, S.-Y.; Haddad, A. Z.; Kumar, A.; Wang, S.-W. Brackish water desalination using reverse osmosis and capacitive deionization at the water-energy nexus. Water Res. 2020, 183, 116064.

(12) Li, S.-L.; Wu, P.; Wang, J.; Wang, J.; Hu, Y. Fabrication of high performance polyamide reverse osmosis membrane from monomer 4-morpholino-m-phenylenediamine and tailoring with zwitterions. Desalination 2020, 473, 114169.

(13) Shin, M. G.; Kwon, S. J.; Park, H.; Park, Y.-I.; Lee, J.-H. Highperformance and acid-resistant nanofiltration membranes prepared by solvent activation on polyamide reverse osmosis membranes. J. Membr. Sci. 2020, 595, 117590.

(14) Yang, Z.; Saeki, D.; Matsuyama, H. Zwitterionic polymer modification of polyamide reverse-osmosis membranes via surface amination and atom transfer radical polymerization for anti-biofouling. J. Membr. Sci. 2018, 550, 332-339.

(15) Veleva, A.; Heath, D.; Johnson, J.; Nam, J.; Patterson, C.; Lannutti, J.; Cooper, S. Interactions between endothelial cells and electrospun methacrylic terpolymer fibers for engineered vascular replacements. J. Biomed. Mater. Res. A 2009, 91 (4), 1131-1139.

(16) Heath, D. E.; Lannutti, J. J.; Cooper, S. L. Electrospun scaffold topography affects endothelial cell proliferation, metabolic activity, and morphology. J. Biomed. Mater. Res. A 2010 94 (4), 1195-1204.
(17) Heath, D. E.; Cooper, S. L. Design and characterization of sulfobetaine-containing terpolymer biomaterials. Acta Biomater 2012, 8 (8), 2899-2910.

(18) Ding, J.; Zhang, J.; Li, J.; Li, D.; Xiao, C.; Xiao, H.; Yang, H.; Zhuang, X.; Chen, X. Electrospun polymer biomaterials. Prog. Polymr. Sci. 2019, 90, 1-34.

(19) Song, X.; Liu, Z.; Sun, D. D. Energy recovery from concentrated seawater brine by thin-film nanofiber composite pressure retarded osmosis membranes with high power density. Energy Environ. Sci. 2013, 6 (4), 1199-1210.

(20) Deshmukh, A.; Boo, C.; Karanikola, V.; Lin, S.; Straub, A. P.; Tong, T.; Warsinger, D. M.; Elimelech, M. Membrane distillation at the water-energy nexus: limits, opportunities, and challenges. Energy Environ. Sci. 2018, 11 (5), 1177-1196.

(21) Liao, Y.; Loh, C.-H.; Tian, M.; Wang, R.; Fane, A. G. Progress in electrospun polymeric nanofibrous membranes for water treatment: Fabrication, modification and applications. Prog. Polymr. Sci. 2018, 77, 69-94.

(22) Kim, J. H.; Park, S. H.; Lee, M. J.; Lee, S. M.; Lee, W. H.; Lee, K. H.; Kang, N. R.; Jo, H. J.; Kim, J. F.; Drioli, E. Thermally rearranged polymer membranes for desalination. Energy Environ. Sci. 2016, 9 (3), 878-884.

(23) Bui, N.-N.; McCutcheon, J. R. Nanofiber supported thin-film composite membrane for pressure-retarded osmosis. Environ. Sci. Technol. 2014, 48 (7), 4129-4136.

(24) Wang, S.; Li, T.; Chen, C.; Kong, W.; Zhu, S.; Dai, J.; Diaz, A. J.; Hitz, E.; Solares, S. D.; Li, T. Transparent, anisotropic biofilm with aligned bacterial cellulose nanofibers. Advanced Functional Materials 2018, 28 (24), 1707491.

(25) Zhang, L.; Gui, J.; Wu, Z.; Li, R.; Wang, Y.; Gong, Z.; Zhao, X.; Sun, C.; Guo, S. Enhanced performance of piezoelectric nanogenerator based on aligned nanofibers and threedimensional interdigital electrodes. Nano Energy 2019, 65, 103924.

(26) Patel, K. H.; Dunn, A. J.; Talovic, M.; Haas, G. J.; Marcinczyk, M.; Elmashhady, H.; Kalaf, E. G.; Sell, S. A.; Garg, K. Aligned nanofibers of decellularized muscle ECM support myogenic activity in primary satellite cells in vitro. Biomedical Materials 2019, 14 (3), 035010.

(27) Tonsomboon, K.; Butcher, A. L.; Oyen, M. L. Strong and tough nanofibrous hydrogel composites based on biomimetic principles. Mater. Sci. Eng. C 2017, 72, 220-227.

(28) Duan, G.; Liu, S.; Jiang, S.; Hou, H. High-performance polyamide-imide films and electrospun aligned nanofibers from an amide-containing diamine. Journal of Materials Science 2019, 54 (8), 6719-6727.

(29) Yao, J.; Chen, S.; Chen, Y.; Wang, B.; Pei, Q.; Wang, H. Macrofibers with high mechanical performance based on aligned bacterial cellulose nanofibers. ACS Applied Materials \& Interfaces 2017, 9 (24), 20330-20339.

(30) Zarghami, S.; Mohammadi, T.; Sadrzadeh, M. Preparation, characterization and fouling analysis of in-air hydrophilic/underwater oleophobic bio-inspired polydopamine coated PES membranes for oily wastewater treatment. J. Membr. Sci. 2019, 582, 402-413.

(31) Rahbari-Sisakht, M.; Ismail, A.; Matsuura, T. Effect of bore fluid composition on structure and performance of asymmetric polysulfone hollow fiber membrane contactor for $\mathrm{CO} 2$ absorption. Separation and purification technology 2012, 88, 99-106.

(32) Franco, J. A.; Kentish, S. E.; Perera, J. M.; Stevens, G. W. Poly (tetrafluoroethylene) sputtered polypropylene membranes for carbon dioxide separation in membrane gas absorption. Industrial \& engineering chemistry research 2011, 50 (7), 4011-4020.

(33) Mulder, J. Basic principles of membrane technology, Springer Science \& Business Media: 2012.

(34) Hoang, T.; Stevens, G.; Kentish, S. The effect of feed pH on the performance of a reverse osmosis membrane. Desalination 2010, 261 (1), 99-103. 
(35) Ghosh, A. K.; Hoek, E. M. Impacts of support membrane structure and chemistry on polyamide-polysulfone interfacial composite membranes. J. Membr. Sci. 2009, 336 (1-2), 140-148.

(36) Darabi, R. R.; Jahanshahi, M.; Peyravi, M. A support assisted by photocatalytic $\mathrm{Fe} 304 / \mathrm{ZnO}$ nanocomposite for thinfilm forward osmosis membrane. Chemical Engineering Research and Design 2018, 133, 11-25.

(37) Yuan, J.; Hung, W.-S.; Zhu, H.; Guan, K.; Ji, Y.; Mao, Y.; Liu, G.; Lee, K.-R.; Jin, W. Fabrication of ZIF-300 membrane and its application for efficient removal of heavy metal ions from wastewater. J. Membr. Sci. 2019, 572, 20-27.

(38) Meng, J.; Lau, C. H.; Xue, Y.; Zhang, R.; Cao, B.; Li, P. Compatibilizing hydrophilic and hydrophobic polymers via spray coating for desalination. J. Mater. Chem. A 2020, 8 (17), 84628468.

(39) Xue, Y. L.; Huang, J.; Lau, C. H.; Cao, B.; Li, P. Tailoring the molecular structure of crosslinked polymers for pervaporation desalination. Nature Communications 2020, 11 (1), 1461.

(40) Song, X.; Gan, B.; Yang, Z.; Tang, C. Y.; Gao, C. Confined nanobubbles shape the surface roughness structures of thin film composite polyamide desalination membranes. J. Membr. Sci. 2019, 582, 342-349.

(41) Song, X.; Gan, B.; Qi, S.; Guo, H.; Tang, C. Y.; Zhou, Y.; Gao, C. Intrinsic Nanoscale Structure of Thin Film Composite Polyamide Membranes: Connectivity, Defects, and Structure-Property Correlation. Environ. Sci. Technol. 2020, 54 (6), 3559-3569.

(42) Li, X.; Li, Z.; Wang, L.; Ma, G.; Meng, F.; Pritchard, R. H.; Gill, E. L.; Liu, Y.; Huang, Y. Y. S. Low-Voltage Continuous Electrospinning Patterning. ACS Applied Materials \& Interfaces 2016, 8 (47), 32120-32131.

(43) Fasano, V.; Laurita, R.; Moffa, M.; Gualandi, C.; Colombo, V.; Gherardi, M.; Zussman, E.; Vasilyev, G.; Persano, L.; Camposeo, A.; Focarete, M. L.; Pisignano, D. Enhanced Electrospinning of Active Organic Fibers by Plasma Treatment on Conjugated Polymer Solutions. ACS Applied Materials \& Interfaces 2020, 12 (23), 26320-26329.

(44) Jana, S.; Cooper, A.; Ohuchi, F.; Zhang, M. Uniaxially Aligned Nanofibrous Cylinders by Electrospinning. ACS Applied Materials \& Interfaces 2012, 4 (9), 4817-4824.

(45) Li, S.; Jo, H. J.; Han, S. H.; Park, C. H.; Kim, S.; Budd, P. M.; Lee, Y. M. Mechanically robust thermally rearranged (TR) polymer membranes with spirobisindane for gas separation. J. Membr. Sci. 2013, 434, 137-147.

(46) Tang, C. Y.; Kwon, Y.-N.; Leckie, J. O. Probing the nano-and micro-scales of reverse osmosis membranes-A comprehensive characterization of physiochemical properties of uncoated and coated membranes by XPS, TEM, ATR-FTIR, and streaming potential measurements. J. Membr. Sci. 2007, 287 (1), 146-156.

(47) Kezia, K.; Lee, J.; Hill, A. J.; Kentish, S. E. Convective transport of boron through a brackish water reverse osmosis membrane. J. Membr. Sci. 2013, 445, 160-169.

(48) Davenport, D. M.; Ritt, C. L.; Verbeke, R.; Dickmann, M.; Egger, W.; Vankelecom, I. F.; Elimelech, M. Thin film composite membrane compaction in high-pressure reverse osmosis. J. Membr. Sci. 2020, 118268.

(49) Shin, M. G.; Park, S.-H.; Kwon, S. J.; Kwon, H.-E.; Park, J. B.; Lee, J.-H. Facile performance enhancement of reverse osmosis membranes via solvent activation with benzyl alcohol. J. Membr. Sci. 2019, 578, 220-229.

(50) Yang, Z.; Guo, H.; Tang, C. Y. The upper bound of thin-film composite (TFC) polyamide membranes for desalination. J. Membr. Sci. 2019, 117297.

(51) Inovenso Nanospinner $416 \quad$ Industrial Electrospinning/Spraying Line. https://www.inovenso.com/portfolio-view/nanospinner416/.

(52) Lee, J. H.; Kim, J.; Liu, D.; Guo, F.; Shen, X.; Zheng, Q.; Jeon, S.; Kim, J. K. Highly aligned, anisotropic carbon nanofiber films for multidirectional strain sensors with exceptional selectivity. Advanced Functional Materials 2019, 29 (29), 1901623. 

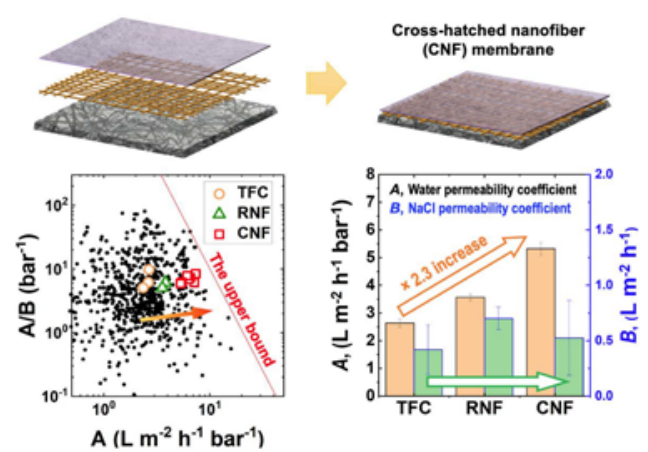


\section{University Library}

\section{- M M N E R VA A gateway to Melbourne's research publications}

Minerva Access is the Institutional Repository of The University of Melbourne

Author/s:

Kim, S;Heath, DE;Kentish, SE

Title:

Composite Membranes with Nanofibrous Cross-Hatched Supports for Reverse Osmosis Desalination

Date:

2020-10-07

Citation:

Kim, S., Heath, D. E. \& Kentish, S. E. (2020). Composite Membranes with Nanofibrous Cross-Hatched Supports for Reverse Osmosis Desalination. ACS APPLIED MATERIALS \& INTERFACES, 12 (40), pp.44720-44730. https://doi.org/10.1021/acsami.0c12588.

Persistent Link:

http://hdl.handle.net/11343/274935 